\title{
STUDIES ON NIACIN BIOSYNTHESIS FROM 3-HYDROXY- ANTHRANILIC ACID IN STREPTOZOTOCIN DIABETIC RATS IN VIVO AND IN VITRO
}

\author{
Nilkanth AKarte and Narayan SHASTRI \\ University Department of Biochemistry, Nagpur University, Nagpur-10, India
}

(Received November 25, 1975)

\begin{abstract}
Summary Biosynthesis of niacin from 3-hydroxyanthranilic acid (3-OHAA) in normal and streptozotocin diabetic rats was studied in vivo and in vitro. Streptozotocin (SZ) diabetic rats were found to excrete lesser quantities of 3-OHAA, quinolinic acid, niacin and $\mathrm{N}^{1}$-methylnicotinamide $(\mathrm{NMN})$ in their urines following 3-OHAA administration than corresponding normal rats. In vitro studies indicated that $\mathrm{SZ}$ diabetic livers form less quinolinic acid from 3-OHAA than normal livers. It appears that this may be due to elevated picolinic carboxylase activity in the livers of $\mathrm{SZ}$ diabetic rats.
\end{abstract}

Biosynthesis of niacin from tryptophan has been found to be affected in diabetic conditions, clinical $(1,2)$ as well as experimental $(3,4)$. The present authors recently reported that SZ-diabetic rats also exhibit faulty conversion of tryptophan into niacin; such rats were observed to excrete lesser quantities of niacin and NMN in their urines following tryptophan administration than the corresponding nondiabetic normal rats (5). SZ-diabetic rats have also been found to excrete comparatively larger quantities of kynurenine, 3-hydroxykynurenine and xanthurenic acid on tryptophan load as compared to the normal nondiabetic rats (6). In view of these observations, it was thought worthwhile to study the effects of suitable intermediates of tryptophan-niacin metabolism on niacin biosynthesis, both in vivo and in vitro with a view to pinpoint the site of the metabolic lesion. Of the three important intermediates-kynurenine, 3-OHAA and 3hydroxykynurenine, only 3-OHAA has been found to be useful in both, in vivo and in vitro, studies. Kynurenine and 3-hydroxykynurenine do not give rise to appreciable quantities of niacin in vitro under the conditions described in this communication. Only 3-OHAA under in vitro conditions is effectively converted into quinolinic acid, which can be converted into niacin by treatment with glacial

Abbreviations used: SZ, streptozotocin; 3-OHAA, 3-hydroxyanthranilic acid; NMN, $\mathrm{N}^{1}$ methylnicotinamide. 
acetic acid (7). In vivo conversion of 3-OHAA into niacin has been reported by TENCONI (4).

The present article describes the experiments conducted to study the conversion of 3-OHAA into niacin in SZ-diabetic rats, both in vivo and in vitro.

\section{EXPERIMENTAL}

Male albino rats of Wistar strain weighing 200-230 g were employed in the present investigations. Some of the rats were made diabetic by intravenous injection of SZ at the level of $65 \mathrm{mg}$ per $\mathrm{kg}$ body weight, dissolved in citrate buffer of $\mathrm{pH}$ 4.5. SZ was kindly supplied by Upjohn International, Inc., Kalamazoo, Michigan, U.S.A. The control rats were injected with the buffer alone. Some of the diabetic and control rats were kept on a niacin-deficient diet for 3 weeks and the remaining animals were kept on a stock laboratory diet. The compositions of both the diets are given in Table 1 .

Table 1. Per cent composition of stock and niacin-deficient diets.

\begin{tabular}{lcc}
\hline \multicolumn{1}{c}{ Constituents } & Stock diet & Niacin-deficient diet \\
\hline Wheat flour & 65 & - \\
Casein & 20 & - \\
Sucrose & - & 57.8 \\
Vitamin-free casein & 10 & 9.0 \\
Ground nut oil & 4 & 8.0 \\
Hawk-Oser salt mixture & $1^{\mathrm{a}}$ & 4.0 \\
Vitamin mixture & - & $20.0^{\mathrm{b}}$ \\
L-Cystine & 0.2 \\
\hline a $1 \mathrm{~g}$ of vitamin mixture in sucrose contained; $10 \mathrm{mg}$ thiamine $\mathrm{HCl}, 20 \mathrm{mg}$ riboflavin, $10 \mathrm{mg}$ \\
pyridoxine $\mathrm{HCl}, 40 \mathrm{mg}$ Ca-pantothenate, $12.5 \mu \mathrm{g}$ folic acid, $200 \mathrm{mg}$ choline, $10 \mu \mathrm{g}$ biotin, \\
$5 \mathrm{mg}$ menadione, $50 \mathrm{mg} \alpha$-tocopherol, $50 \mathrm{mg}$ niacin, $10 \mu \mathrm{g}$ cyanocobalamin, $2,000 \mathrm{I} . \mathrm{U}$. \\
$\quad$ vitamin A and 200 I.U. vitamin D. \\
b $20 \mathrm{~g}$ of vitamin mixture in sucrose contained; $10 \mathrm{mg}$ thiamine $\mathrm{HCl}, 20 \mathrm{mg}$ riboflavin, \\
$10 \mathrm{mg}$ pyridoxine $\mathrm{HCl}, 40 \mathrm{mg}$ Ca-pantothenate, $12.5 \mu \mathrm{g}$ folic acid, $200 \mathrm{mg}$ choline, $10 \mu \mathrm{g}$ \\
biotin, $5 \mathrm{mg}$ menadione, $50 \mathrm{mg} \alpha$-tocopherol, $10 \mu \mathrm{g}$ cyanocobalamin, $2,000 \mathrm{I} . \mathrm{U}$. vitamin \\
A and 200 I.U. vitamin D.
\end{tabular}

Rats kept on a niacin-deficient diet were transferred to metabolic cages after 3 weeks and their urines collected and analysed. Then they were injected with 3-OHAA and the urine samples for the following $24 \mathrm{hr}$ were collected under toluene and analysed. The results obtained are presented in Table 2.

3-OHAA was determined by the method of Brown and Price as described by TENCONI (4), quinolinic acid and niacin in urine were determined by the cyanogen bromide method described by TENCONI (4) and NMN estimation was carried out by the procedure described by HufF and PerlzweIG ( 8 ).

Rats kept on stock laboratory diet were used for in vitro studies after 15 
Table 2. Urinary tryptophan metabolites in normal and SZ-diabetic rats kept on niacin-deficient diet for 3 weeks, before and after intraperitoneal injection of

3-OHAA. Values $(\mu \mathrm{g} / \mathrm{rat} / \mathrm{day} \pm$ S.D. $)$ are averages of experiments on 5 rats and 5 determinations.

\begin{tabular}{|c|c|c|c|c|c|}
\hline \multirow{2}{*}{ Metabolite } & & \multicolumn{2}{|c|}{ Nondiabetic } & \multicolumn{2}{|c|}{ Diabetic } \\
\hline & & Before & After & Before & After \\
\hline \multirow[t]{2}{*}{ 3-OHAA } & 1 & $57 \pm 10$ & $226 \pm 26$ & $68 \pm 20$ & $173 \pm 38$ \\
\hline & 2 & $54 \pm 14$ & $200 \pm 31$ & $52 \pm 17$ & $120^{a} \pm 35$ \\
\hline \multirow[t]{2}{*}{ Quinolinic acid } & 1 & - & $510 \pm 101$ & - & $340^{\mathrm{a}} \pm 84$ \\
\hline & 2 & - & $630 \pm 100$ & - & $420^{a} \pm 95$ \\
\hline \multirow[t]{2}{*}{ Niacin } & 1 & $15 \pm 4$ & $35 \pm 8$ & $10 \pm 5$ & $20^{a} \pm 4$ \\
\hline & 2 & $14 \pm 5$ & $48 \pm 11$ & $11 \pm 4$ & $22^{b} \pm 7$ \\
\hline \multirow[t]{2}{*}{$\mathrm{NMN}$} & 1 & $78 \pm 15$ & $330 \pm 52$ & $68 \pm 14$ & $115^{b} \pm 27$ \\
\hline & 2 & $95 \pm 14$ & $407 \pm 60$ & $80 \pm 11$ & $154^{b} \pm 30$ \\
\hline
\end{tabular}

1. $10 \mathrm{mg} 3$-OHAA per rat; $2.50 \mathrm{mg} 3-\mathrm{OHAA}$ per $\mathrm{kg}$ body weight.

a $P<0.05 ;$ b $P<0.01$.

Table 3. In vitro biosynthesis of quinolinic acid ${ }^{\mathrm{a}}$ from 3-OHAA in the liver homogenates of normal and SZ-diabetic rats. Values are averages of 8 flasks, 8 rats, each flask containing $300 \mathrm{mg}$ liver and S.D.

\begin{tabular}{lccccc}
\hline \multirow{2}{*}{ Substrate } & \multicolumn{4}{c}{ Niacin $(\mu \mathrm{g}$ per flask) } \\
\cline { 2 - 3 } & \multicolumn{2}{c}{ Water treatment } & & \multicolumn{2}{c}{ Glacial acetic acid treatment } \\
\cline { 2 - 3 } \cline { 5 - 6 } & Normal & Diabetic & & Normal & Diabetic \\
\hline None & $48.4 \pm 6.2$ & $42.2 \pm 5.0$ & & $69.5 \pm 5.8$ & $52.3 \pm 8.2$ \\
0.5 mg 3-OHAA & $45.4 \pm 7.1$ & $39.8 \pm 6.3$ & & $202 \pm 21$ & $108^{\mathrm{b}} \pm 12$ \\
1 mg 3-OHAA & $50.0 \pm 7.8$ & $44.2 \pm 4.9$ & & $400 \pm 30$ & $206^{\mathrm{c}} \pm 19$ \\
\hline
\end{tabular}

a Quinolinic acid estimated as niacin after conversion by the acetic acid treatment.

b $P<0.01 ;$ c $P<0.001$.

days of SZ injections. The animals, both diabetic and control, were killed and their livers rapidly removed, chilled and then homogenized in cold Ringer-phosphate buffer of $\mathrm{pH} 7.4$. Substrates, as described in Table 3, were added to $3 \mathrm{ml}$ of homogenate (100 mg liver per $\mathrm{ml}$ ) placed in a flask and shaken for $3 \mathrm{hr}$ at $37^{\circ} \mathrm{C}$. The incubation mixtures were then treated according to the procedures described by HENDERSON and RAMSARMA (7). Untreated samples were transferred to test tubes which were placed in a boiling water bath for 3 min. Sulphuric acid treatment was carried out by adding $10 \mathrm{ml}$ glacial acetic acid to the samples and autoclaving at $15 \mathrm{lbs}$ for $2 \mathrm{hr}(7) . \mathrm{pH}$ of the samples was adjusted to 6.8 and the samples made to definite volume. Niacin content of the samples was determined colorimetrically by the cyanogen bromide method of Swaminathan (9). The difference between the niacin values of the incubation mixture containing no precursor and a mixture containing a precursor, after acetic acid treatment, gives the amount of quinolinic acid biosynthesised by the system from the precursor. 
Quinolinic acid is expressed here as niacin after its conversion into niacin by the acid treatment.

\section{RESULTS AND DISCUSSION}

Table 2 indicates the urinary excretion of tryptophan-niacin metabolites in normal and SZ-diabetic rats kept on a niacin-deficient diet before and after administration of 3-OHAA. Excretion of all the metabolites examined increased after 3-OHAA injection, but the increase in the excretion of quinolinic acid, niacin and NMN was significantly less in diabetic rats as compared to the normal controls. Diabetic rats also tended to exhibit lower urinary values of 3-OHAA.

Results obtained with in vitro studies are presented in Table 3. Homogenates containing 3-OHAA and treated with glacial acetic acid exhibited higher values of niacin as compared to the flasks without the addition of 3-OHAA and treated with glacial acetic acid. The increase in niacin values was, however, significantly less in the livers of SZ-diabetic rats. $P$ values in Table 3 indicate the level of significance in the difference in the increase in value of the metabolite in the diabetic rats after the treatment in vivo and in vitro as compared to the normal rats. The results thus indicate that the diabetic livers convert 3-OHAA into quinolinic acid significantly less than the normal livers.

It has been reported that in alloxan-diabetic rats there is a marked elevation in the activity of the hepatic picolinic carboxylase (10). This enzyme is involved in the conversion of the oxidation product of 3-OHAA into picolinic acid. The increased activity of this enzyme will divert the niacin biosynthetic pathway towards picolinic acid, thereby causing reduced formation of quinolinic acid and consequently of niacin. IKEDA et al. (11) have noted a decrease in NAD synthesis in alloxan-diabetic rats in vivo and in vitro, which they contribute to the elevated hepatic picolinic carboxylase activity. Pancreatectomized rats have also been found to exhibit faulty niacin biosynthesis from 3-OHAA in vivo (4) and in vitro(12).

It appears that the results reported in this paper may be due to a similar metabolic lesion in SZ-diabetic rats. Experiments conducted in this laboratory have indicated about fourfold increased activity of picolinic carboxylase in SZ-diabetic livers as compared to that of normal control livers (unpublished data), as a result of which the metabolic pathway from 3-OHAA to niacin is diverted largely towards picolinic acid. This may thus be a contributing factor in the reduced conversion of 3-OHAA into quinolinic acid, and ultimately niacin, in the SZ-diabetic rats.

The authors wish to express their grateful thanks to Prof. V. G. Hatwalne for his valuable suggestions and to the Indian Council of Agricultural Research, New Delhi, for awarding a Senior Research Fellowship to N. R. Akarte and financial assistance.

\section{REFERENCES}

1) Rosen, D. A., Mengwyn, D., Becker, B., Stone, H. H., and Freidenwald, J. S., Proc. 
Soc. Exp. Biol. Med., 88, 321 (1955).

2) Kotake, Y. and TANI, S., J. Biochem. (Tokyo), 40, 295 (1963).

3) McDaniel, E. G., Hundley, J. M., and Sebrell, W. H., J. Nutr., 59, 407 (1956).

4) Tenconi, L. T., Acta Vitaminol., 5, 193 (1964).

5) Akarte, N. R. and Shastri, N. V., Diabetes, 23, 977 (1974).

6) Akarte, N. R. and Shastri, N. V., communicated for publication.

7) Henderson, L. M. and Ramsarma, G. B., J. Biol. Chem., 181, 687 (1949).

8) Huff, J. W. and Perlzweig, W. A., J. Biol. Chem., 167, 157 (1947).

9) Swaminathan, M., Indian J. Med. Res., 26, 427 (1938).

10) Mehler, A. H., MCDaniel, E. G., and Hundley, J. M., J. Biol. Chem., 232, 323 (1958).

11) Ikeda, M., Tsuji, H., Nakamura, S., Ichiyama, A., Nishizuka, Y., and Hayaishi, O., $J$. Biol. Chem., 240, 1395 (1965).

12) Bonomi, V., Ginoulhiac, E., and Tenconi, L. T., Acta Vitaminol., 18, 219 (1964). 